\title{
Hospital Inpatient Tracking System Using RFID Technology
}

\author{
CHIA CHIN LING \& STEPHANIE HUI LI CHUA* \\ Faculty of Computer Science and Information Technology, Universiti Malaysia Sarawak, 94300 Kota \\ Samarahan, Sarawak, Malaysia \\ *Corresponding authors: chlstephanie@unimas.my
}

\begin{abstract}
Hospital Inpatient Tracking System using RFID technology is a web application developed for the medical personnel (doctors and nurses) to track the movements of the inpatients in the accident and emergency department of government hospitals. RFID reader fixed in each of the rooms will detect the patient who is wearing the registered tag when enter and leave from the room. It is designed to solve the problems of long queues, overcrowding, delayed treatments, and insufficient beds for patients. Tracking process is taken to track all of the registered patient. At the same time, duration of patient process in each of the room will be recorded and calculated to get the range of processing time in each of the room. It can be used as reference and solving the bottlenecks that faced by hospitals. All the medical personnel need to register and approved by system administrator before accessible to the system.
\end{abstract}

Keywords: Patient tracking, RFID technology, web application

Copyright: This is an open access article distributed under the terms of the CC-BY-NC-SA (Creative Commons Attribution-NonCommercial-ShareAlike 4.0 International License) which permits unrestricted use, distribution, and reproduction in any medium, for non-commercial purposes, provided the original work of the author(s) is properly cited.

\section{INTRODUCTION}

The Accident and Emergency Department (A \& E) in general hospital provides care to patients who arrive following an accident or with an emergency medical condition without prior appointment. All patients will be triaged and given priority status by determining according to the condition of the patient. Patients belonging to the non-priority status category will be requested to register at the registration counter first. Then, the patients will be seen by the doctor following the visit number. The patients will be categorized into three zones that are green, yellow and red zone. Green zone states that the patient which is an outpatient and can be discharged directly after treatment. Yellow zone states that the patient is an inpatient who needs to be observed and may need to be admitted. Red zone states that the patient which is an inpatient with serious condition and needs to be admitted. After consultation, the patient will be admitted, observed or discharged. The inpatient in the yellow and red zone will be admitted to the wards and will undergo treatment and medical checkup processes for example X-Ray, Blood Test and Physiotherapy. Finally, the inpatient either will be discharged from the hospital, transferred to other hospital or transferred to the mortuary for deceased cases. This is the current scenario for the movement of patients from admission to A \& E until the patient is being discharged from the hospital.

The current scenario for the A\&E of government hospitals, where A\&E is having problems of long queue, overcrowding, delayed and not enough bed for patients (Eller, 2018). Next, the medical personnel, which are doctors and nurses tracking their patients' movements using phone call or oral asking among the others. This tracking process is currently done manually in the hospital. A lot of time will be wasted and maybe will missed out the patients if tracking the patients' movements manually. Then, the security of the patients in the hospital cannot be ensured because the medical personnel cannot track the location of patients by 24 hours.

The objectives of the project were

i. To design the Hospital Inpatient Tracking System (HITS) Using RFID Technology.

ii. To develop the layout of HITS as a web application.

iii. To test the proposed HITS through the simulation cases. 


\section{Related work}

Several existing systems, which is related to the proposed application are discussed and compared. The first existing system is Mobile RFID Kids Tracking System - Al-Ali, Aloul, Aji, Al-Zarouni and Fakhro (2018) proposed a mobile tracking system using RFID technology. This tracking system is designed for the kids. The objective of their project was to track the lost kids in a large open area. Movements of the kids in an open area, such as a park or mall can be tracked using RFID technology. The tag readers are distributed around the open area. The kids wear the RFID tags can communicate between the tag reader by antenna and the signals are sent to the web server via wireless LANs. Location of the kids will be displayed in the system. Route taken by the child by plotting the last detected position can be shown and the parents are able to connect with their kids.

The second existing system is an application using RFID technology in Patient Management System Mapa and Saha (2015) proposed an application using RFID technology in Patient Management System. The objective of their project was to minimize the time serving a patient by identifying the patient, type of service required, history of treatment, waiting time and accessing personal information. Each of the patients will be given a passive RFID tag with personal information during registration in the hospital. Data is collected from the time the patient who enters into a processing area until being discharged. The range of processing time and the chart for each patient can be simulated from the data collected to conclude the processes of each department.

The third existing system is Indoor Positioning System using Ultrasonic Technology - Al Kahf, Mian and Lim (2016) proposed a project for Indoor Tracking System using Ultrasonic technology. The objective of their project was to track the location of an elderly mother who is stay alone in the house. Band will wear by the user on the wrist. The band in one of the rooms will listen to the ultrasonic pulses. Once the ultrasound pulse is captured, the band will send it to the Hub to compute the band's position. Table 1 below shows the comparison between the three systems states above and the proposed application.

\section{TOOLS AND TECHNOLOGY USED}

Several tools and technologies were used in the proposed application.

\section{Laravel}

Laravel (https://www.tutorialspoint.com/laravel/laravel_overview.htm.) is an open-source tool for PHP framework. This was used for the development of the proposed application. It helps in creating a web application which can be designed in a more structured and pragmatic. It has a set of features, which can help increase the speed in developing the web application. For example, the features include modularity, testability, routing, configuration management, query builder and ORM, schema builder, template engine, email, authentication, Redis, queues, event and command bus. Furthermore, a website built in Laravel is secure and prevents web attacks. Composer is a tool consisting of all the dependencies and libraries which are needed to install first before the installation of Laravel. With the help of this framework, the proposed application can be done in a more scalable way and can save the time in designing the web application

\section{ХАМРP}

XAMPP (Mikoluk, 2013) is an open-source software that was used for the development of this proposed application. It is used to create a local web server or local host for testing purposes. The components to set up a web server are all included in XAMPP. They are server application (Apache), database (MySQL), MariaDB and scripting language (PHP). The transitioning from a local test server to the live server is easy because XAMPP has the same components with the actual web server. Furthermore, XAMPP can function across all platforms on the Linux, Mac and Windows.

\section{Bootstrap}

Bootstrap is an open-source tool for CSS framework that will be used to design the interface for this proposed application. It contains HTML, CSS, and JS based design template for the forms, buttons, and others. Bootstrap was chosen to be used in the development of the interface for this proposed application because it can speed up the building of a responsive web application. 
Table 1. Comparison between the existing system and proposed application

\begin{tabular}{|c|c|c|c|c|}
\hline Function and Features & $\begin{array}{l}\text { Mobile RFID Kids } \\
\text { Tracking System }\end{array}$ & $\begin{array}{l}\text { Application using RFID Technology } \\
\text { in Patient Management System }\end{array}$ & $\begin{array}{l}\text { Indoor Positioning System } \\
\text { Using Ultrasonic Technology }\end{array}$ & Proposed System \\
\hline Indoor tracking the locations of people & Yes & Yes & Yes & Yes \\
\hline $\begin{array}{l}\text { Display the location tracked in the } \\
\text { system }\end{array}$ & Yes & Yes & Yes & Yes \\
\hline Plot the last detected position & Yes & No & No & No \\
\hline Record the time spent for each process & No & Yes & No & Yes \\
\hline Simulate the range of processing time & No & Yes & No & Yes \\
\hline $\begin{array}{l}\text { Download range of processing time } \\
\text { report }\end{array}$ & No & No & No & Yes \\
\hline Display the discharged list in system & No & No & No & Yes \\
\hline $\begin{array}{l}\text { Exceeded waiting time alert for the } \\
\text { patient due to different type of room }\end{array}$ & No & No & No & Yes \\
\hline Search engine & No & Yes & No & Yes \\
\hline $\begin{array}{l}\text { Control the Hub trigger a single cluster } \\
\text { of devices only }\end{array}$ & No & No & Yes & No \\
\hline Type of device & $\begin{array}{l}\text { RFID active tag with } \\
\text { fixed RFID reader }\end{array}$ & $\begin{array}{l}\text { RFID passive tag with fixed RFID } \\
\text { reader }\end{array}$ & $\begin{array}{l}\text { Ultrasonic-based band and } \\
\text { slaves }\end{array}$ & $\begin{array}{l}\text { RFID passive tag } \\
\text { with fixed RFID } \\
\text { reader }\end{array}$ \\
\hline Type of technology & RFID technology & RFID technology & Ultrasonic technology & RFID technology \\
\hline
\end{tabular}




\section{RFID Technology}

Radio-Frequency Identification (RFID) was used in this proposed application for tracking the real time locations of patients. RFID is a technology that uses radio waves to identify people or objects from a distance automatically. It consists of readers and tags. The RFID tag is a microchip which is connected to the antenna, acts as a transducer which sends the signal to the reader (Jia, Feng, Fan \& Lei, 2012). The active RFID reader then communicates with the tag to capture the data. It can capture the data with high reading speed. When in longer read range, fast scanning and flexible data carrying capability is required.

\section{METHODOLOGY}

The methodology used for this project was the Rapid Application Development (RAD) cycle, going through the process of requirements analysis and design, prototype cycles and testing.

The requirements for this proposed application were gathered and analyzed to produce a high-quality application, which fulfill the requirements needed. Then, the design for the proposed application is carried out based on the requirements needed. There was system architecture design, module design, database design and user interface design. All of them were ready to continue for producing a systematic application with an idea.

\section{Requirements}

Functional Requirements are listed as below:

a) Admin can login directly into the system with the given staff id and password.

b) Admin need to validate the user after the registration process.

c) Admin can manage users' accounts with delete, search, and view.

d) Admin can manage the reader section that needed to be tracked with add, edit, delete, search, and view.

e) Admin can manage the exceeded waiting time alert for the patient according to different reader section.

f) Admin can view the range of processing time tracking details in each reader section.

g) User need to register and login to the system.

h) User can manage patients' details with add, edit, delete, search and view.

i) User can check the location of patient.

j) User can check total patients list, total inpatients list, total staff list and the discharged patients list.

k) User can get the exceeded waiting time alert in the system due to the patient who are waiting over the maximum waiting time in the room.

1) User can check the tag whether it is existing.

m) User can view the duration for the patient stay in each of the room.

n) User can view the chart for the tracking data.

o) User can generate and download different type of according to the tracking data.

p) User can view and update the profile.

Non-Functional Requirements are listed as below:

a) User need wait for the registration confirmation by admin before access into the system.

b) User allowed to change the login password if forgot the password.

c) Only the basic information of patient allowed to show in the system to ensure the privacy of patient.

d) New discharged patient must be highly visible in the discharged list.

\section{System architecture design}

System architecture design is an overview system design for the proposed application with conceptual representation of the components and subcomponents. System architecture diagram for this proposed application is shown in the Figure 1. 


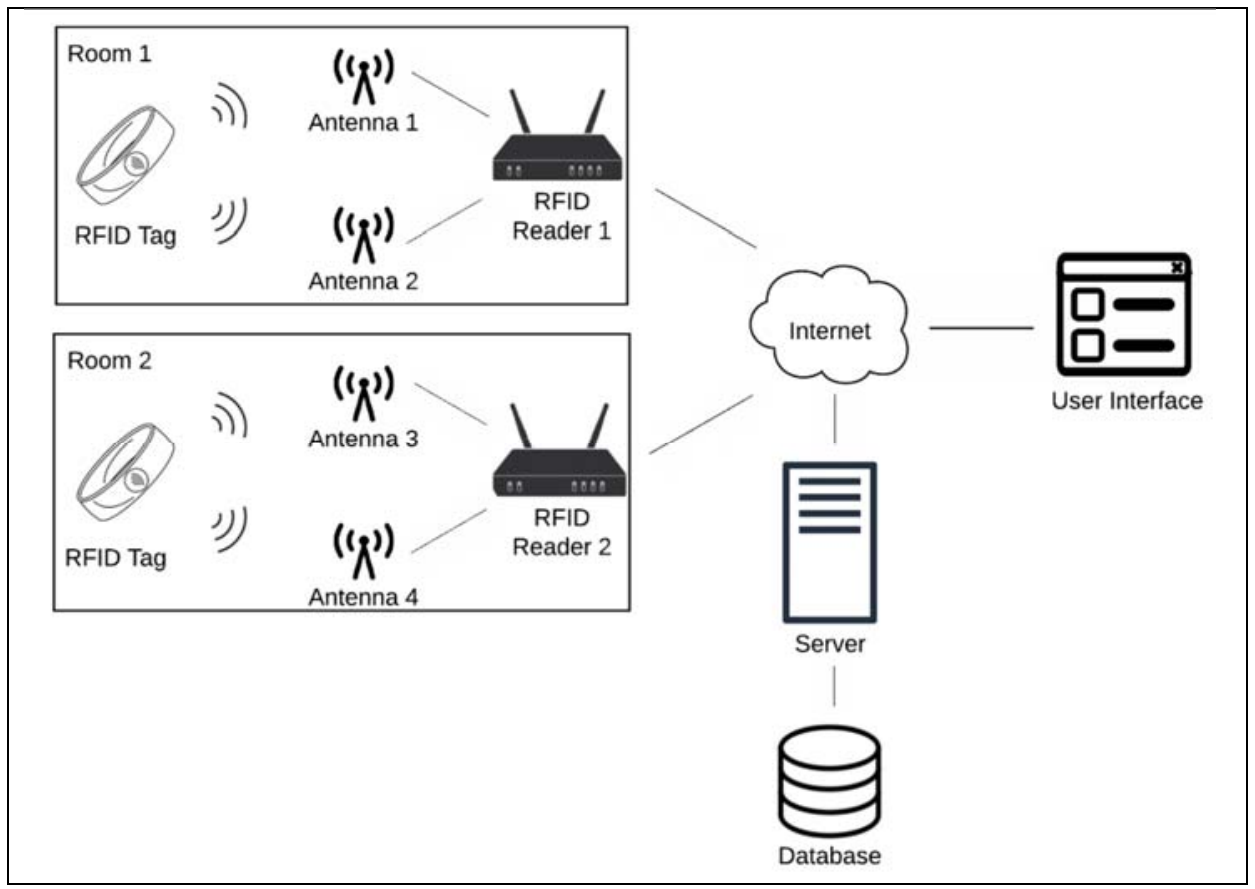

Figure 1. System Architecture Diagram in HITS

\section{Module Design}

Context diagram is shown in Figure 2. The proposed application in this project is HITS. The inputs and outputs flow with the external entities are required in the context diagram. The medical personnel need to send the registration and approval request to the HITS and wait for the approval from the system administrator who is successfully login. The details of medical personnel will be shown to the system administrator. After successfully register and login, the medical personnel can register the patient who will be tracked through managing the patient's details. Then, the system administrator needs to update the reader section details in HITS. The RFID tracker will send the tracker information to HITS. Finally, patient's tracking details list and the range of processing time details will be shown to the medical personnel and admin in HITS.

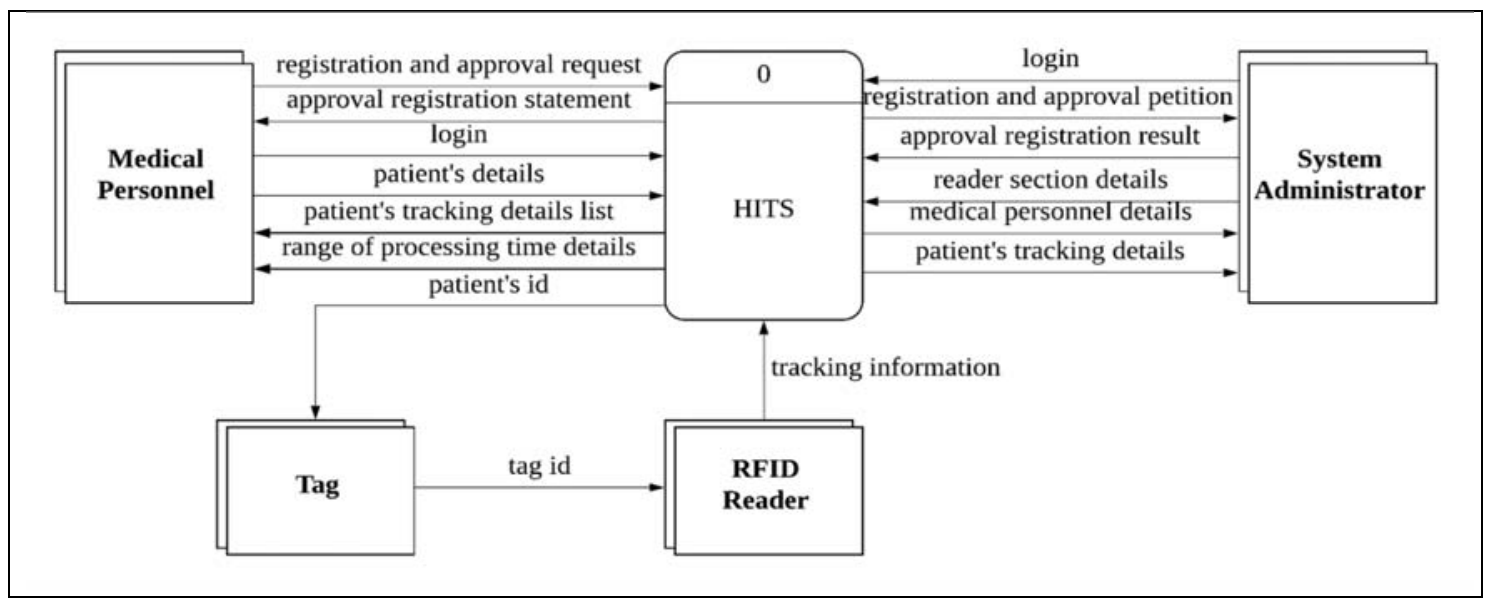

Figure 2. Context Diagram in HITS 
Figure 3 shows the Level 0 data flow diagram in HITS. System administrator can access the system by providing the username and password with the validation of user record. The medical personnel are required to register and wait for the approval from system administrator before accessing the system. All of the data will be stored in the user record. After successful approval, they can manage the patient tracking. The data will be updated and stored in the patient record. System administrator can manage the reader section details and store in the reader record. Then, the patient and reader section details with the tag id from tag will be retrieved and send the information to the RFID reader which is detected with the tag id. The tracking details stored will be displayed to the medical personnel and admin. It is then used for generating the chart of range of processing time.

\section{Database design}

Figure 4 shows an Entity Relationship diagram for the HITS. Entity relationship diagram is used to design the relational databases for this proposed application. It is a type of flowchart that demonstrate the relativity between entities. There are six tables in the database. They are users, patients, tags, readers, tracks and history table. User can manage the patients and readers. Each of the patient can only put on one tag. Then, the tags and readers details will be including in the tracking table after detected by RFID reader. The patient discharged will be deleted from tracks table and stored in history table.

\section{User Interface Design}

Figure 5, 6 and 7 show the user interface design of main page for system administrator and medical personnel.

\section{IMPLEMENTATION AND TESTING}

The implementation process was done based on the requirement analysis and design with the development tools and technology.

Then, the testing process was taken to ensure the requirements and objectives of this proposed application can be achieved. Developer site testing is a test case to determine whether each of the functional requirement is working as expected. Each of the test case includes ID, test description, step details, expected result and actual result. The test cases on login page, registration page, email notification, new user request, manage reader section, manage user, manage patient, check exist tag, tracking, dashboard, generate report and user profile are tested for functionality. All of test cases were successfully tested and showed the actual results as expected with all the status pass for this proposed application. The test cases are shown in Table 2 to Table 13.

\section{CONCLUSION AND FUTURE WORK}

The proposed application, HITS was successfully designed, developed and tested, which fulfill all the requirements. However, this project still has several weaknesses due to the developer's experience, technical skills and knowledge, lack of resources and software limitation. The weaknesses and limitations of this web application can be improved in the future to increase the quality of this web application. This project can consists the long distances detection RFID technology with reader, antenna and passive tags. Passive RFID inlay is suggested for patient to wear. These are the parts of the improvement can be made for this proposed application. 
Trends in Undergraduate Research (2020) 3(2): c1-15 https://doi.org/10.33736/tur.2729.2020

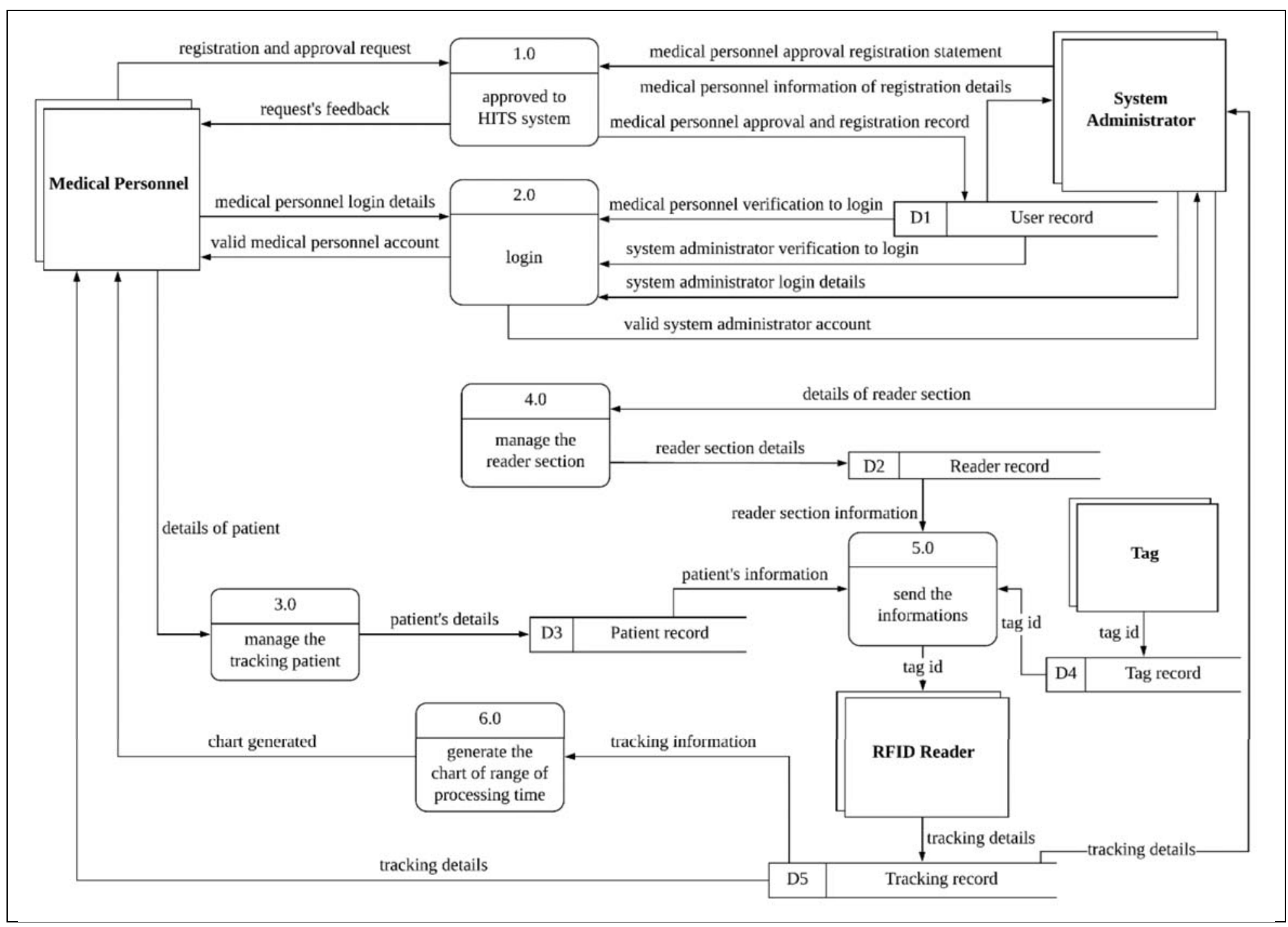

Figure 3. Level 0 Data Flow Diagram in HITS 
Trends in Undergraduate Research (2020) 3(2): c1-15

https://doi.org/10.33736/tur.2729.2020

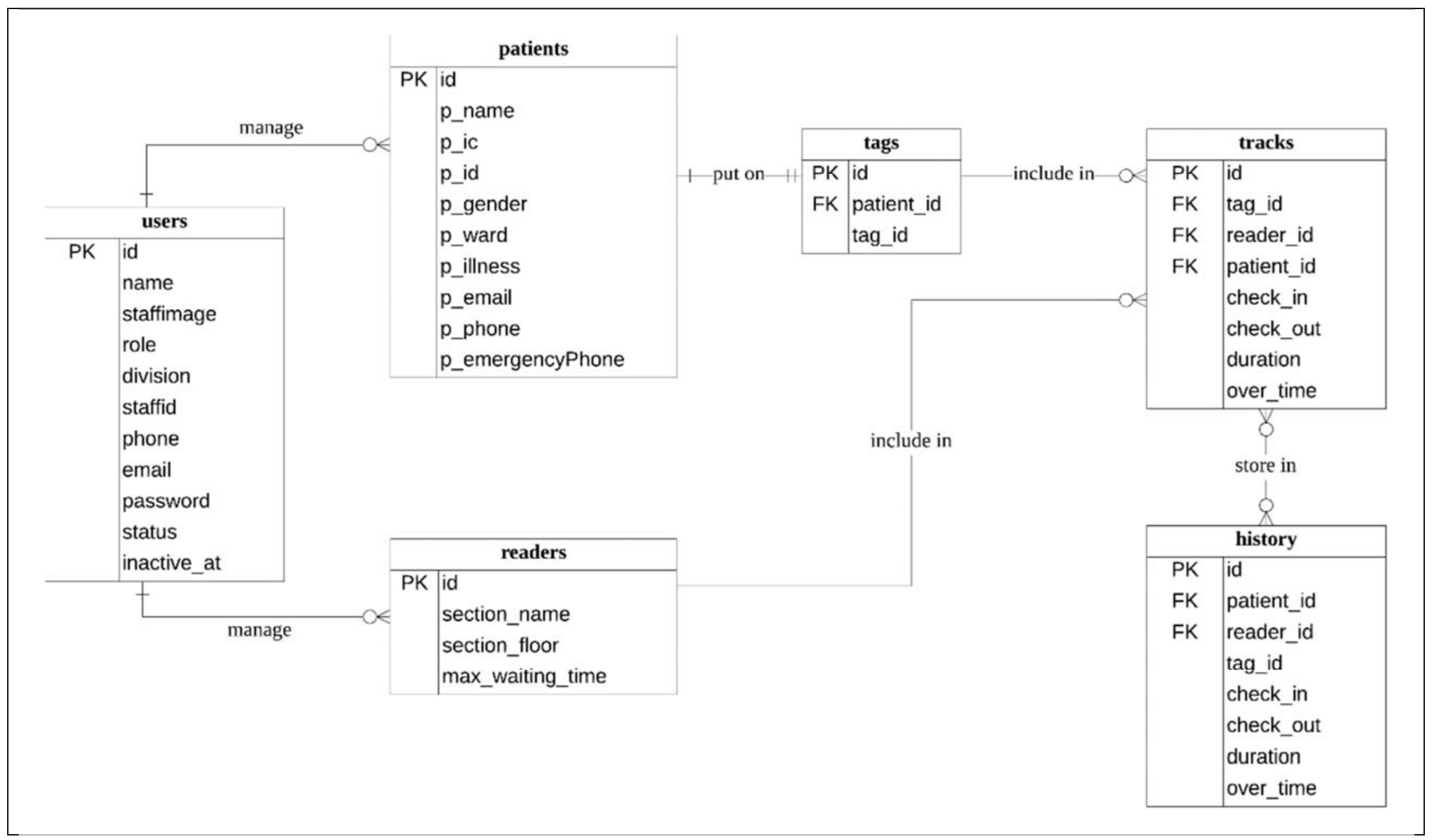

Figure 4. Entity Relationship Diagram 


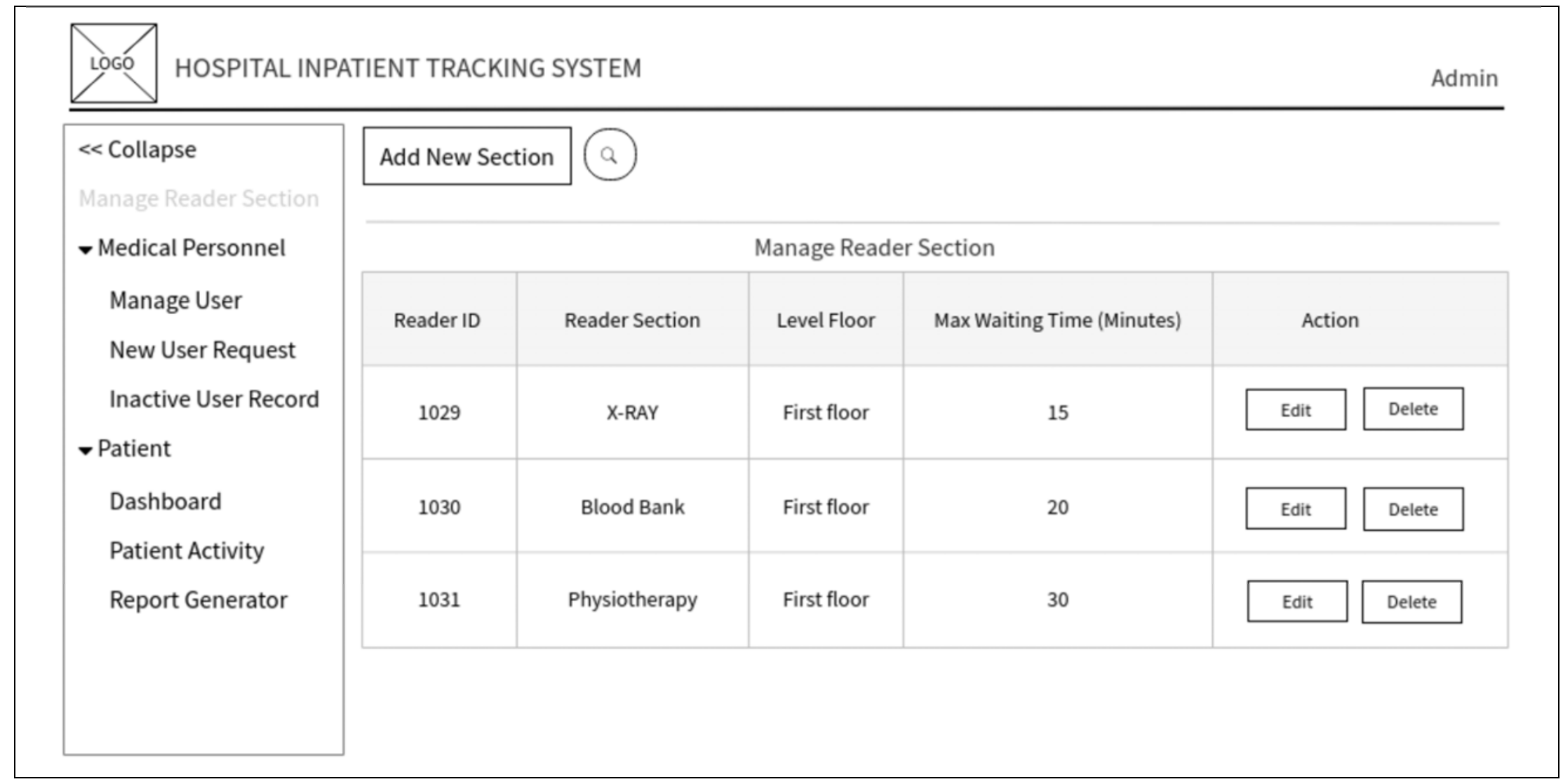

Figure 5. User Interface Design of System Administrator (Manage Reader Section) 


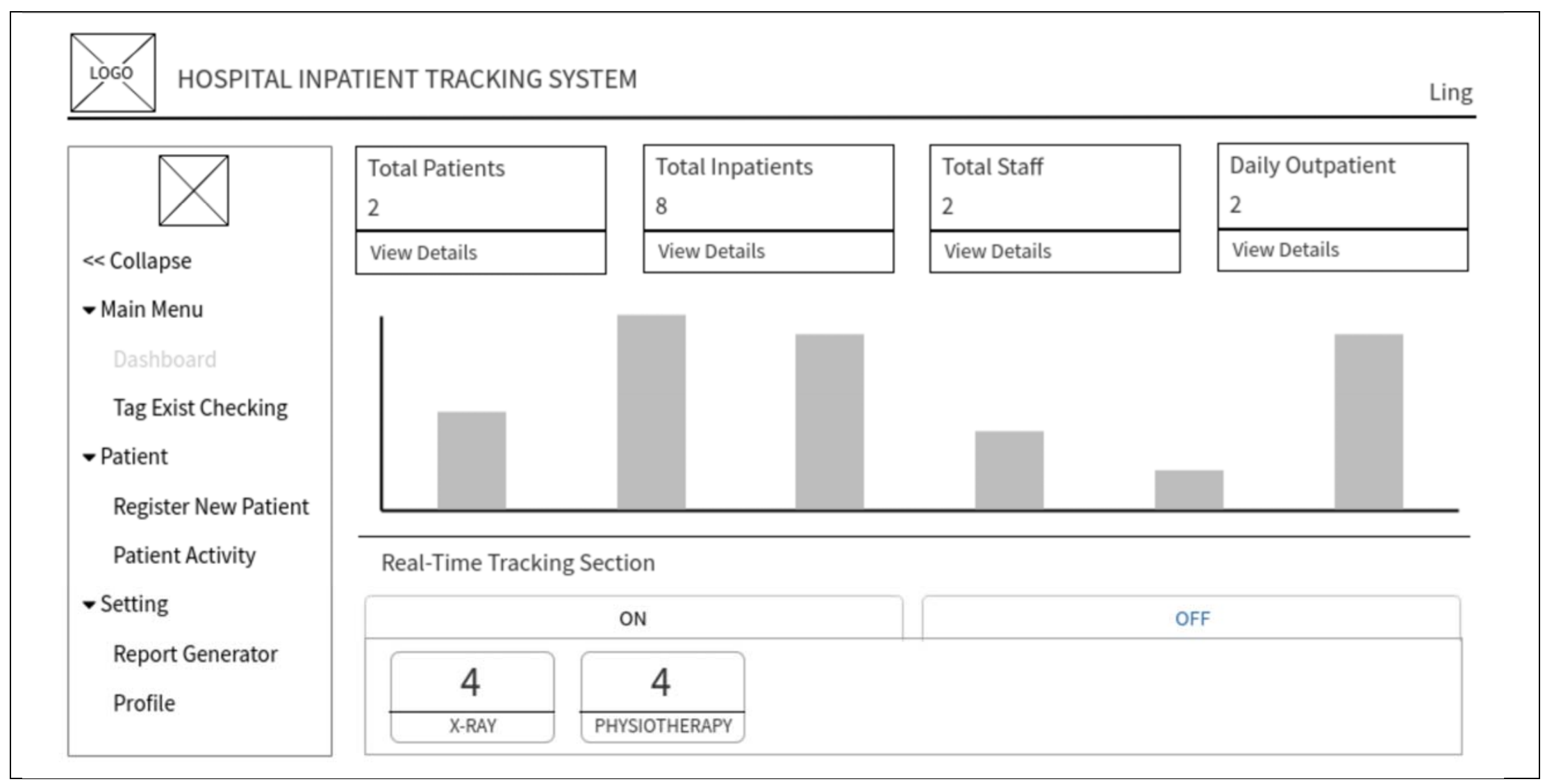

Figure 6. User Interface Design of Medical Personnel (Dashboard) 


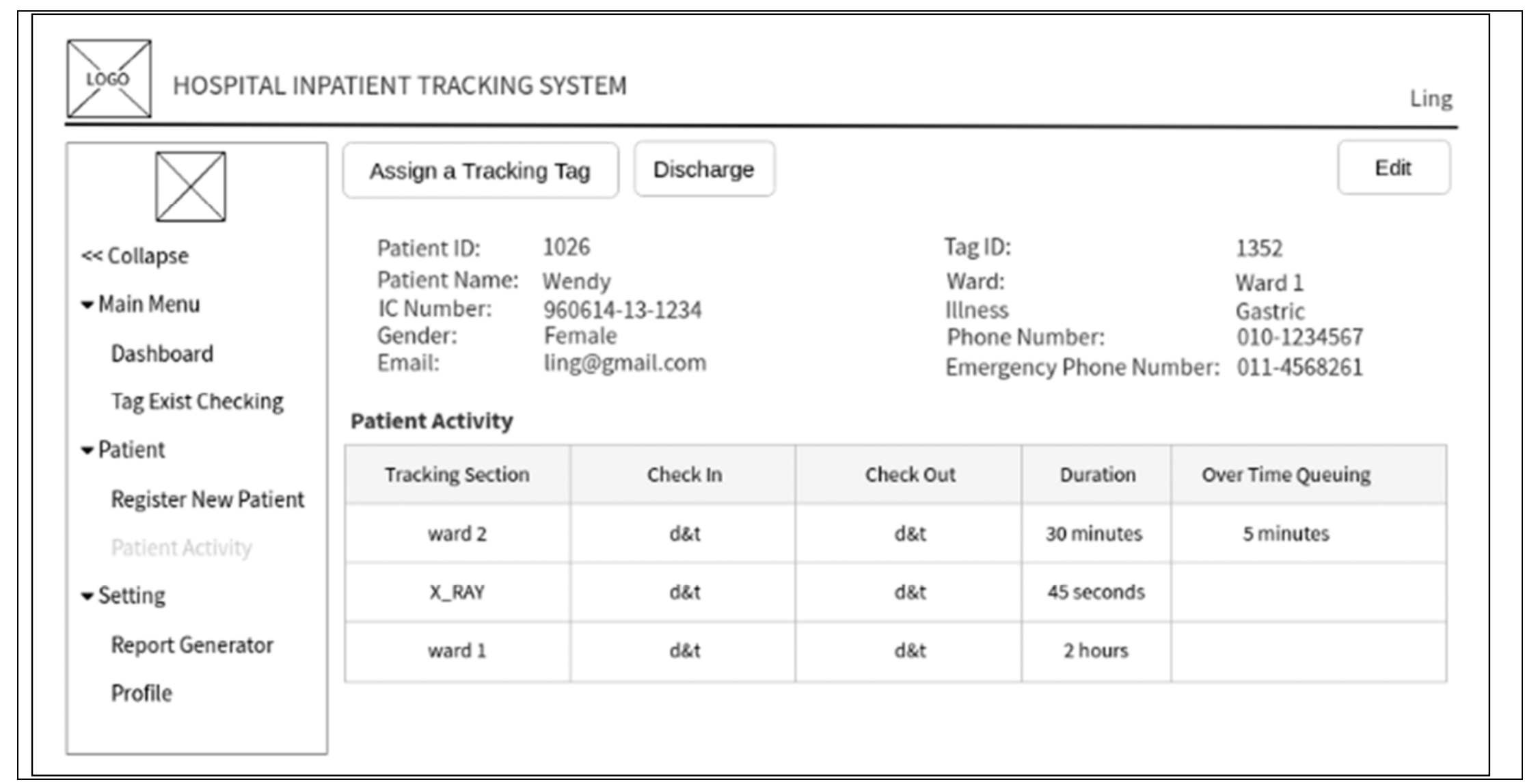

Figure 7. User Interface Design of Medical Personnel (Patient Activity) 
Table 2. Test case on login page.

\begin{tabular}{lllll}
\hline $\begin{array}{l}\text { Test Case: } \\
\text { Test Description: }\end{array}$ & \multicolumn{1}{l}{ TC01 } & & & \\
\hline$\#$ & Step Der can login to the application & Expected Results & Actual Results & Status \\
\hline 1 & Enter staff id and password & Credential can be entered & As Expected & Pass \\
2 & Click login & User is logged in & As Expected & Pass \\
\hline
\end{tabular}

Table 3. Test case on registration page.

\begin{tabular}{lllll}
\hline $\begin{array}{l}\text { Test Case: } \\
\text { Test Description: }\end{array}$ & \multicolumn{1}{l}{ TC02 } & & & \\
\hline$\#$ & Step Der can register to the application & Expected Results & Actual Results & Status \\
\hline 1 & Register user's account & User's validated details are added to the database & As Expected & Pass \\
2 & Reset registration form & User registration form is cleared & As Expected & Pass \\
3 & Waiting approval & Registered user proceeds to waiting approval page & As Expected & Pass \\
\hline
\end{tabular}

Table 4. Test case on email notification.

\begin{tabular}{|c|c|c|c|c|c|}
\hline \multirow{2}{*}{\multicolumn{2}{|c|}{$\begin{array}{l}\text { Test Case: } \\
\text { Test Description: }\end{array}$}} & \multicolumn{4}{|l|}{$\mathrm{TC} 03$} \\
\hline & & \multicolumn{4}{|c|}{ User and admin can receive email notification } \\
\hline \# & Step Details & & Expected Results & Actual Results & Status \\
\hline 1 & \multicolumn{2}{|c|}{$\begin{array}{l}\text { User sends email notification } \\
\text { after registration }\end{array}$} & $\begin{array}{l}\text { Admin received email notification of new } \\
\text { user request }\end{array}$ & & \\
\hline 2 & \multicolumn{2}{|c|}{$\begin{array}{l}\text { Admin sends email notification } \\
\text { after approve user }\end{array}$} & $\begin{array}{l}\text { User received email notification of } \\
\text { approving result }\end{array}$ & As Expected & Pass \\
\hline 3 & \multicolumn{2}{|c|}{$\begin{array}{l}\text { Admin sends email notification } \\
\text { after reject user }\end{array}$} & $\begin{array}{l}\text { User received email notification of } \\
\text { rejected result }\end{array}$ & As Expected & Pass \\
\hline
\end{tabular}

Table 5. Test case on new user request.

\begin{tabular}{llcll}
\hline $\begin{array}{l}\text { Test Case: } \\
\text { Test Description: }\end{array}$ & TC04 & & \\
\hline$\#$ & Step Details & Expected Results & Actual Results & Status \\
\hline 1 & Click approve & New user is approved and can be logged in & As Expected & Pass \\
2 & Click reject & New user is rejected and cannot be log in & As Expected & Pass \\
\hline
\end{tabular}


Table 6. Test case on manage reader section.

\begin{tabular}{|c|c|c|c|c|c|}
\hline \multicolumn{2}{|c|}{$\begin{array}{l}\text { Test Case: } \\
\text { Test Description: }\end{array}$} & \multicolumn{4}{|c|}{ ( } \\
\hline \# & Step Details & & Expected Results & Actual Results & Status \\
\hline 1 & Add new read & section & New reader section is added to database & As Expected & Pass \\
\hline 2 & Edit reader's & & Reader's detail is edited and updated to database & As Expected & Pass \\
\hline 3 & Delete reader & ction & Reader section is deleted to database & As Expected & Pass \\
\hline 4 & $\begin{array}{l}\text { Search reader } \\
\text { detail in table }\end{array}$ & ction's & $\begin{array}{l}\text { Reader section's detail is searched based on the } \\
\text { table }\end{array}$ & As Expected & Pass \\
\hline
\end{tabular}

Table 7. Test case on manage user.

\begin{tabular}{lllll}
\hline $\begin{array}{l}\text { Test Case: } \\
\text { Test Description: }\end{array}$ & \multicolumn{1}{l}{ TC06 } \\
Admin can manage user & & \\
\hline$\#$ & Step Details & Expected Results & Actual Results & Status \\
\hline 1 & View user's detail & User's detail is viewed by admin & As Expected & Pass \\
2 & Search user's detail in table & User's detail is searched based on the table & As Expected & Pass \\
3 & Deactivate user's account & User access is revoked & As Expected & Pass \\
4 & Activate user's account & User account is activated and able to login & As Expected & Pass \\
\hline
\end{tabular}

Table 8. Test case on manage patient.

\begin{tabular}{|c|c|c|c|c|}
\hline \multicolumn{2}{|c|}{$\begin{array}{l}\text { Test Case: } \\
\text { Test Description: }\end{array}$} & \multicolumn{3}{|c|}{$\begin{array}{l}\text { TC07 } \\
\text { User can manage patient }\end{array}$} \\
\hline \# & Step Details & Expected Results & Actual Results & Status \\
\hline 1 & Add patient's detail & Patient's detail is added to database & As Expected & Pass \\
\hline 2 & View patient's detail & Selected patient's detail is viewed by user & As Expected & Pass \\
\hline 3 & $\begin{array}{l}\text { Search patient's detail } \\
\text { in table }\end{array}$ & Patient's detail is searched based on the table & As Expected & Pass \\
\hline 4 & Edit patient's detail & Patient's detail is edited and updated to database & As Expected & Pass \\
\hline 5 & Assign a tracking tag & $\begin{array}{l}\text { Patient is assigned with a tracking tag and added to } \\
\text { database }\end{array}$ & As Expected & Pass \\
\hline 6 & Edit tracking tag & Tracking tag is edited and updated to database & As Expected & Pass \\
\hline 7 & Discharge patient & Patient is discharged from tracking & As Expected & Pass \\
\hline
\end{tabular}

Table 9. Test case on check exist tag.

\begin{tabular}{|c|c|c|c|c|c|}
\hline \multirow{2}{*}{\multicolumn{2}{|c|}{$\begin{array}{l}\text { Test Case: } \\
\text { Test Description: }\end{array}$}} & \multicolumn{4}{|l|}{ TC08 } \\
\hline & & \multicolumn{4}{|c|}{ User can check the tag whether is existing } \\
\hline \# & Step Details & & Expected Results & Actual Results & Status \\
\hline 1 & \multicolumn{2}{|c|}{ Scan the tag to check } & Tag is scanned as requested to check & As Expected & Pass \\
\hline 2 & \multicolumn{2}{|c|}{$\begin{array}{l}\text { Show the checked tag with } \\
\text { patient's detail }\end{array}$} & $\begin{array}{l}\text { Patient's detail is checked from database } \\
\text { and displayed }\end{array}$ & As Expected & Pass \\
\hline
\end{tabular}


Table 10. Test case on tracking.

\begin{tabular}{lllll}
\hline $\begin{array}{l}\text { Test Case } \\
\text { Test Description }\end{array}$ & \multicolumn{1}{l}{ TC09 } \\
User can track the patient & & \\
\hline \# & Step Details & Expected Results & Actual Results & Status \\
\hline & $\begin{array}{l}\text { Scan the tracking tag of } \\
\text { assigned patient with RFID } \\
\text { reader }\end{array}$ & $\begin{array}{l}\text { The tracking tag ID is read by RFID reader } \\
\text { and request as input in the hidden text box of }\end{array}$ & As Expected & Pass \\
& $\begin{array}{l}\text { Differentiate the reader } \\
\text { section when patient is } \\
\text { scanned }\end{array}$ & $\begin{array}{l}\text { The different reader section is detected when } \\
\text { the patient is scanned with different laptop }\end{array}$ & As Expected & Pass \\
\hline
\end{tabular}

Table 11. Test case on dashboard.

\begin{tabular}{|c|c|c|c|c|c|}
\hline \multirow{2}{*}{\multicolumn{2}{|c|}{$\begin{array}{l}\text { Test Case: } \\
\text { Test Description: }\end{array}$}} & \multicolumn{4}{|l|}{$\mathrm{TC} 010$} \\
\hline & & \multicolumn{4}{|c|}{ User and admin can view overall details in dashboard } \\
\hline \# & Step Details & & Expected Results & Actual Results & Status \\
\hline 1 & \multicolumn{2}{|c|}{$\begin{array}{l}\text { list, total staff list and the discharged } \\
\text { patients list. }\end{array}$} & Patient and staff details are viewed & As Expected & Pass \\
\hline 2 & \multicolumn{2}{|c|}{$\begin{array}{l}\text { Get exceeded waiting time alert in } \\
\text { each reader section }\end{array}$} & $\begin{array}{l}\text { Different type of color alert in each } \\
\text { reader section is viewed }\end{array}$ & As Expected & Pass \\
\hline 3 & \multicolumn{2}{|c|}{ View the chart with tracking data } & Chart with tracking data is viewed & As Expected & Pass \\
\hline
\end{tabular}

Table 12. Test Case on Generate Report

\begin{tabular}{lllll}
\hline $\begin{array}{l}\text { Test Case } \\
\text { Test Description }\end{array}$ & \multicolumn{1}{l}{ TC011 } & & \\
\hline$\#$ & Step Details & Expected Results & Actual Results & Status \\
\hline 1 & $\begin{array}{l}\text { Generate different type of chart } \\
\text { with tracking data as report }\end{array}$ & $\begin{array}{l}\text { Different type of chart with tracking } \\
\text { data is generated }\end{array}$ & As Expected & Pass \\
2 & Download the chart & Chart is downloaded & As Expected & Pass \\
\hline
\end{tabular}

Table 13. Test Case on User Profile

\begin{tabular}{lllll}
\hline $\begin{array}{l}\text { Test Case: } \\
\text { Test Description: }\end{array}$ & TC012 & & \\
\hline$\#$ & Step Details & Expected Results & Actual Results & Status \\
\hline 1 & View user profile & User's detail is viewed & As Expected & Pass \\
2 & Edit the user profile & User profile is edited and updated to database & As Expected & Pass \\
3 & Change password & Password is changed and updated to database & As Expected & Pass \\
\hline
\end{tabular}


Trends in Undergraduate Research (2020) 3(2): c1-15

https://doi.org/10.33736/tur.2729.2020

\section{ACKNOWLEDGEMENTS}

The authors would like to express sincere gratitude to Universiti Malaysia Sarawak

\section{REFERENCES}

Al-Ali, A. R., Aloul, F. A., Aji, N. R., Al-Zarouni, A. A. \& Fakhro, N. H. (2008). Mobile RFID Tracking System. In $20083^{\text {rd }}$ International Conference on Information and Communication Technologies. From Theory to Applications (pp 1-4). IEEE

Al Kahf, M. Y., Mian, S. \& Lim, J. Y. (2016). 4th Year Project - Indoor Positioning System. Retrieved October 8, 2019 from https://www.slideshare.net/MYahiaAlKahf/4th-year-project-indoor-positioning-system.

Eller, J. (2018). IoT Find and Track: The Next Generation of Healthcare - DZone IoT. Retrieved October 5, 2018 from https://dzone.com/articles/iot-find-and-track-the-next-generation-of-healthca.

Jia, X., Feng, Q., Fan, T. \& Lei, Q. (2012). RFID technology and its applications in Internet of Things (IoT). Proceedings of $20122^{\text {nd }}$ International Conference on Consumer Electronics, Communications and Networks (pp. 1282-1285). IEEE

Mapa, L. \& Saha, K. (2015). Application of RFID technology in patient management system. Proceedings of $122^{\text {nd }}$ ASEE Annual Conference \& Exposition: Making Value for Society, 2015, Seattle, Washington State.

Mikoluk, K. (2013). XAMPP Tutorial: How to Use XAMPP to Run Your Own Web Server. Retrieved October 12, 2019 from https://blog.udemy.com/xampp-tutorial/. 